\title{
EFFECTS OF PEPTIDES DERIVED FROM THE ANTARCTIC SCALLOP ADAMUSSIUM COLBECKI ON OBESE RATS' ADIPOSE TISSUE HISTOPHYSIOLOGY
}

\author{
Nataliia Raksha ${ }^{1 凶}$, Olesia Kalmukova ${ }^{2}$, Tetiana Vovk ${ }^{1}$, Tetiana Halenova ${ }^{1}$, Mykola \\ Dzerzhynsky $^{2}$, Olexiy Savchuk ${ }^{1}$, Ludmila Ostapchenko ${ }^{1}$ \\ ${ }^{1}$ Department of Biochemistry, Educational and Scientific Centre "Institute of Biology and Medicine", Taras \\ Shevchenko National University of Kyiv, Kyiv, Ukraine \\ ${ }^{2}$ Department of Cytology, Histology and Reproductive Medicine, Educational and Scientific Centre "Institute of \\ Biology and Medicine”, Taras Shevchenko National University of Kyiv, Kyiv, Ukraine \\ $\otimes_{\text {nkudina2021@gmail.com }}$ \\ https://doi.org/10.34302/crpjfst/2021.13.4.3 \\ Article history: \\ Received: \\ 18 July 2021 \\ Accepted: \\ 18 November 2021 \\ Keywords: \\ High-calorie diet-induced \\ obesity; \\ Visceral white adipose tissue; \\ Antarctic marine hydrobiont; \\ Low grade inflammation; \\ Mast cells.

\begin{abstract}
The researchers have currently investigated the possibilities of organisms from extreme living conditions as sources to obtain active biomolecules for therapy of different metabolic diseases including obesity. The purpose of the present study was to evaluated the effect of functionally active peptides derived from the tissues of Antarctic scallop (PAS) Adamussium colbecki on rat's visceral white adipose tissue (WAT) state during high-calorie dietinduced obesity development. It has been found that after daily oral administration of PAS at a dose of $5 \mathrm{mg} \cdot \mathrm{kg}-1$ of body weight for 6 weeks, obese rat's WAT histophysiology was improved, which was manifested in the decline in chronic inflammation due to decrease in the relative visceral fat weight, the size of white adipocytes, the fibrosis level in WAT and the crown-like structure presence in comparison with the rats, which were on a high-calorie diet (HCD). In addition, the body weight gain and the mast cell number in WAT of the rats with PAS showed an intermediate value, as they did not differ from both control and HCD groups. These data allow suggesting that oral administration of PAS to obese rats affects WAT inflammatory state and, in particular, ameliorates complications after HCD intakes.
\end{abstract}

\section{Introduction}

The bivalve Antarctic scallop (Adamussium colbecki) is recognized as an endemic to Antarctic waters (Cerrano et al., 2006; Cronin et al., 2020). Nowadays, the psychrophiles - the organisms that live in extremely low temperatures (usually $-20^{\circ} \mathrm{C}-$ $+10^{\circ} \mathrm{C}$ ), have been actively investigated to obtain new active biomolecules for different aims (biotechnology industry, pharmacology etc.) (Bhatia et al., 2021). Marine organisms are considered a valuable source of bioactive compounds with high nutraceutical and pharmaceutical potentials. The biodiversity of the marine environment constitutes a practically unlimited resource to obtain biologically active substances. In recent years, special attention is focused on the hydrobionts of the Antarctic region which are poorly explored. To adapt to very exigent and aggressive surroundings these organisms produce plenty of molecules that may differ structurally from the terrestrial analogs. It is widely known that proteins of marine organisms have good functionality, high nutritional value, and therefore they could serve as a source to produce low-molecular-weight fragments or/and peptides (Baty et al., 2007). 
Adamussium colbecki may be a novel source of cold-adapted proteolytic enzymes, antioxidants, and probiotic substrate. In our previous studies (Raksha et al., 2016; Raksha et al., 2020a), we found highly active enzymes (fibrino(geno)lytic and trypsin-like) in the crude extract of this hydrobiont. In addition, Adamussium colbecki exhibits higher activities of catalase, glutathione reductase, and glutathione peroxidases compared with the Mediterranean species (Benedetti et al., 2017). Also, many species of mollusks are included as an important compound in the Mediterranean diet (Tuttolomondo et al., 2019), usage of which demonstrated some efficiency in decreasing adiposity and improving cardiovascular risk factors in overweight/obese adult humans with metabolic syndrome and/or diabetes (Salas-Salvadó et al., 2019).

The aim of this study was to investigate the influence of functionally active peptides derived from the tissues of Antarctic scallop (PAS) Adamussium colbecki on the rats' visceral WAT (relative visceral fat weight, white adipocytes size, crown-like structure, tissue fibrosis level and presence of mast cells) in high-calorie diet-induced obesity.

\section{Materials and methods}

\subsection{Isolation of functionally active proteins} from the tissues of Antarctic scallop (PAS) Adamussium colbecki.

The soft tissues of the hydrobiont were hydrolyzed to produce the peptides. According to the necessity to obtain a fraction of peptides that would fully maintain the biological activity, the use of acid or alkaline hydrolysis, despite their high efficiency, is inappropriate. Therefore, enzymatic hydrolysis was chosen. Hydrolysis was performed using trypsin (3000 $\mathrm{U} \cdot \mathrm{g}-1$ protein) at $37^{\circ} \mathrm{C}$ and $\mathrm{pH} 8.0$ for $24 \mathrm{~h}$. The degree of hydrolysis was determined by sodium dodecyl sulfate polyacrylamide gel electrophoresis in $10 \%$ polyacrylamide gel. The hydrolysis was stopped by boiling the sample to inactivate the enzyme. The hydrolysate was then centrifuged at $10000 \mathrm{~g}$ for $15 \mathrm{~min}$. The peptide fraction was prepared by microfiltration using a membrane with a molecular weight cutoff (MWCO) of $5 \mathrm{kDa}$. The obtained peptide fraction was further lyophilized. After dissolving the peptide lyophilizate in $0.9 \%$ $\mathrm{NaCl}$, it was used for animal studies as the fraction of peptides derived from the tissues of marine hydrobiont.

\subsection{Animals and Experimental design of high calorie diet-induced obesity (HCD).}

Sixty albino nonlinear male rats with an initial body mass of $110 \pm 10 \mathrm{~g}$ were used in this study. All experiments on animals were performed in compliance with the international principles of the European Convention for the Protection of Vertebrate Animals used for Experimental and Other Scientific Purposes (Strasbourg, 1986), Directive 2010/63/EU of the European Parliament and of the Council of 22 September 2010 on the protection of animals used for scientific purposes, Article 26 of the Law of Ukraine "On the Protection of Animals from Cruelty" (No. 3447-IV, dated February 21, 2006), as well as all norms of bioethics, biological safety, and the general ethical principles of experiments on animals adopted by the First National Congress of Ukraine on Bioethics (September, 2001). All manipulations were approved by the Ethical Committee of Educational and Scientific Centre "Institute of Biology and Medicine" Taras Shevchenko National University of Kyiv.

The experiments started after 7 days of animal acclimation in the animal facility of Taras Shevchenko National University of Kyiv, maintained under constant conditions of temperature $\left(22 \pm 3{ }^{\circ} \mathrm{C}\right)$, humidity $(60 \pm 5 \%)$, and light (12 h light/12 h dark cycle). Standard rodent food and water were provided ad libitum. For the first week, all rats had ad libitum access to standardized food "Purina rodent chow" and water. On the 8th day, animals were randomly divided into two groups (20 and 40 animals). Rats of the first group were fed with a standard ration $(3.81 \mathrm{kcal} / \mathrm{g})$, whereas those of the second group received a 
high-calorie diet (HCD) $(5.35 \mathrm{kcal} / \mathrm{g})$. The high-calorie chow included $60 \%$ standard food composition, $10 \%$ pork fat, $10 \%$ hen eggs, $9 \%$ sucrose, $5 \%$ peanut, $5 \%$ dry milk, and $1 \%$ vegetable oil (Halenova et al., 2018). To confirm the development of obesity the animals were weighed one time a week until the average body gain reached a significant difference of at least $30 \%$ between the two groups. After that, HCD group was divided into two subgroups (20 animals in each subgroup), so in sum we have 3 groups:

1) rats without treatment fed with a standard ration (Control group);

2) rats fed with a HCD (HCD group);

3) rats fed with a HCD and receive administration of PAS (HCD+PAS group).

PAS was administered by intragastric (i.g.) at a dose of $5 \mathrm{mg} \cdot \mathrm{kg}^{-1}$ of body weight every other day for the next 6 weeks.

Food and water consumption were measured daily at the same time (09:00 to 10:00 h) and body weights were determined once a week. Body weight gain, relative daily food (kcal/day/g body weight) and relative daily water consumption ( $\mathrm{ml} /$ day/per rat) was determined for each rat. In the last day of the experiment the epididymal, retroperitoneal, perirenal fat pads were dissected and immediately weighed and relative visceral fat weight was calculated.

\subsection{Histology examination.}

On the last day of the experiment, the animals were removed from the experiment by decapitation by guillotine, and visceral white adipose tissues (WAT) from perirenal localization were taken out. WAT were fixed in $4 \%$ paraformaldehyde in $0.1 \mathrm{M}$ phosphate buffer for $72 \mathrm{~h}$, dehydrated and embedded into paraffin wax. From the paraffin blocks, $5 \mu \mathrm{m}$ sections were prepared and stained with Hematoxylin and Eosin (H\&E).

\subsection{Histochemical detection of tissue collagen content (fibrosis level) in WAT.}

Detection of collagen fibers was carried out using histochemical picrofucsin by Van Gieson trichrome staining with addition of hematoxylin to visualize nuclei (Mishra et al., 2015). For quantitative determination of tissue collagen content, microphotographs were obtained using an objective with $4 \times$ magnification; for each subsequent microphotography, the field of view was moved to the right, retaining $20 \%$ of the previous field until the entire cut was taken. To create one large composite panoramic image, the cross-linking software Adobe Photoshop CS6 (Adobe Systems, USA) was used. From each image, the area of the red-stained region (red - collagen fibers) was calculated and expressed as a percentage of the total area.

\subsection{Histochemical detection of mast cells in WAT. \\ Mast cells were detected by staining in a} $0.1 \%$ aqueous solution of toluidine blue (Altintas et al., 2011).

Subsequent research was performed using a light microscope Olympus BX41 (Japan). Microphotographs were obtained using the Olympus DP20 (Japan) digital camera and the QuickPHOTO MICRO software (Promicra, Czech Republic). The cross-sectional area of white adipocytes, the number of mast cells and crown-like structure (CLS), tissue fibrosis (the area occupied by collagen fibers) were measured using ImageJ software (National Institutes of Health, USA).

\subsection{Statistical analysis.}

SPSS 16.0 software was employed for data analysis. The normality of data distribution was determined by the Kolmogorov-Smirnov test. Significance of the observed changes was assessed by parametric (one-way ANOVA with Tukey's post hoc multiple comparison tests) and nonparametric (Kruskal-Wallis test for independent samples) methods. $\mathrm{P}<0.05$ indicated a statistically significant difference. 
The results obtained are presented as mean \pm standard error of the mean (SEM).

\section{Results and discussions}

\subsection{Body weight changes, relative WAT mass} changes, food and water intake.

The body weight gain in the HCD rats increased by $40 \%$ in comparison with the control group (Table 1). The value of body weight gain in the rats of HCD+PAS group was at an intermediate state: it did not differ from either the control or the HCD group. Nevertheless, the relative visceral fat weight in HCD+PAS group demonstrated significant difference between HCD group: its value decreased by $30 \%$; and also, between the control group: its value increased only by $17 \%$.
In contrast, the relative weight of visceral fat in the HCD group increased by $65 \%$ in comparison to the control. It should be emphasized that the change in the relative weight of visceral fat in the HCD + PAS group was not correlated with the decrease in food intake, since the relative daily food intake in the HCD + PAS group was as high as in the HCD group (the values are increased by $32 \%$, and $36 \%$, respectively, compared with the control). The relative daily water intake was decreased in the HCD and HCD+PAS groups by $17 \%$ and $24 \%$, respectively, compared with the control. Obtained data indicate that there is no effect of PAS on the relative daily intake of food and water.

Table 1. Body weight gain, relative daily water and food consumption, visceral fat weight of experimental groups of animals.

\begin{tabular}{|c|c|c|c|}
\hline Parameters & Control group & HCD group & HCD + PAS group \\
\hline Body weight gain (\%) & $195 \pm 23$ & $271 \pm 17 *$ & $235 \pm 23$ \\
\hline Relative visceral fat weight (\%) & $1.78 \pm 0.03$ & $2.93 \pm 0.31 *$ & $2.08 \pm 0.03 * \#$ \\
\hline $\begin{array}{c}\text { Relative daily food consumption } \\
\text { (kcal/day/g body weight) }\end{array}$ & $0.251 \pm 0.002$ & $0.344 \pm 0.002 *$ & $0.332 \pm 0.006^{*}$ \\
\hline $\begin{array}{c}\text { Relative daily water consumption } \\
\text { (ml/day per rat) }\end{array}$ & $38.9 \pm 0.7$ & $32.2 \pm 0.4 *$ & $29.5 \pm 1.5 *$ \\
\hline
\end{tabular}

Data are presented as the $\mathrm{M} \pm \mathrm{SEM}$;

$* \mathrm{p}<0.05$ compared with the control value,

$\# \mathrm{p}<0.05$ compared with the HCD group

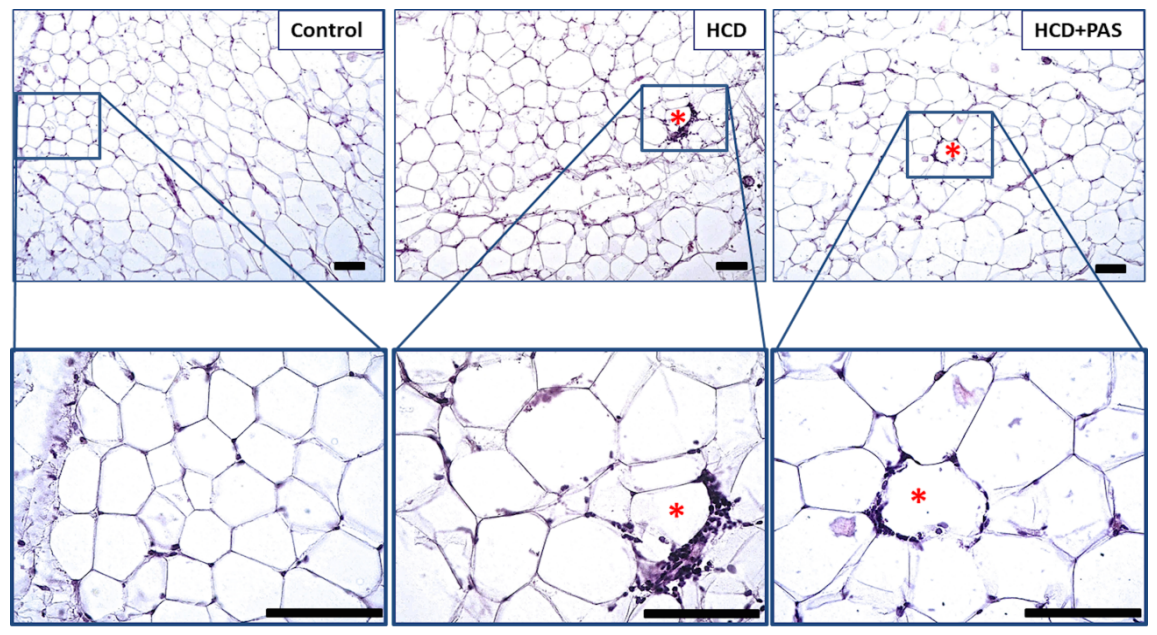

Figure 1. Microscopic appearance of the rats' WAT sections of Control, HCD, HCD+PAS group: H\&E staining; scale bar $100 \mu \mathrm{m}$. Note, asterisk - crown-like structure 

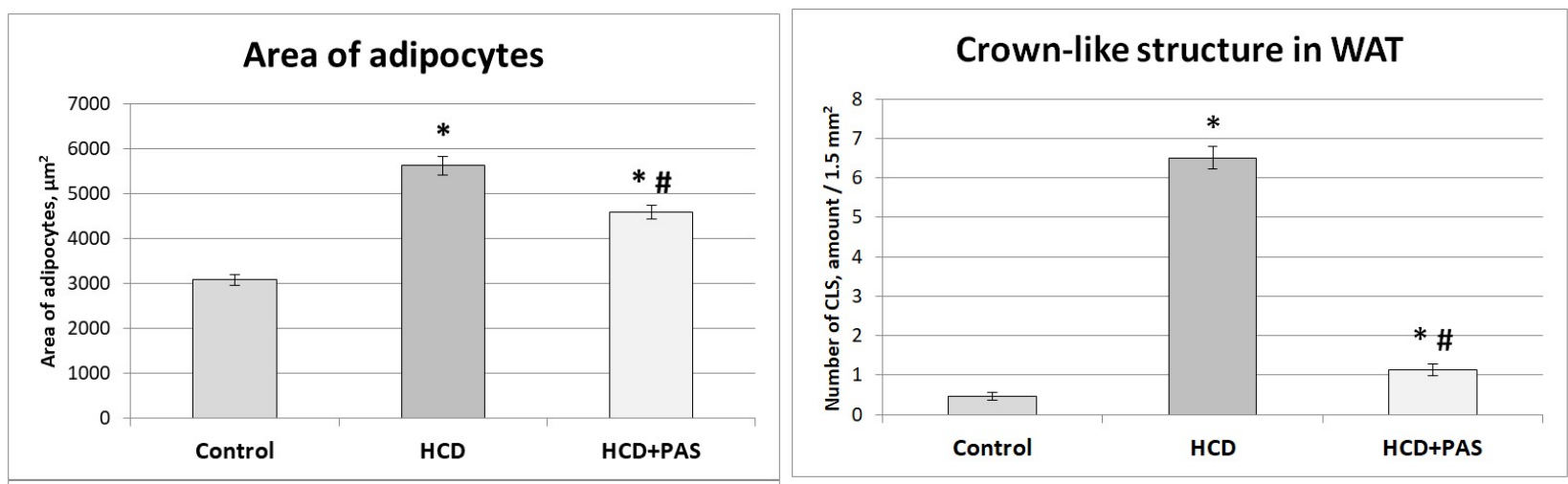

Figure 2. Results of WAT morphometric analysis: CLS number and cross-section area of white adipocytes. Data are presented as the $\mathrm{M} \pm \mathrm{SEM}$; ${ }^{*}-\mathrm{p}<0.05$ compared with control value, \# $-\mathrm{p}<0.05$ compared with HCD.

\subsection{Histology examination of WAT.}

As shown in Figure 1 (asterisk), the crownlike structures (CLS) appear in WAT of obese rats - dead adipocytes, which are surrounded by leukocytes. CLS is the one of chronic inflammation markers in WAT. In the rats that received PAS (HCD+PAS) remain to appear CLS, however with a lower number of leukocytes. Morphometric assay (Figure 2) of WAT reveals an increase in CLS in the HCD group by 14-fold compared with the control. The administration of PAS (group HCD+PAS) leads to a decrease in CLS by 5.7-fold compared with the HCD group, but this value is increased by 2.5-fold compared with the control. The adipocytes area was increased in the HCD group by $85 \%$ in comparison with the control, while in the HCD+PAS group only by $50 \%$ (that is smaller by $18 \%$ in comparison with the HCD group).

\subsection{Fibrosis level in WAT.}

During developing obesity, the inflammation state of WAT changes, which manifests in chronic mild status (Figure 3). These connect with leukocyte infiltration (Figure 3, arrow head) and collagen fibers deposition rising in WAT of HCD group. Markedly, collagen fiber deposition increased not only in the connective tissue septa between lobules of adipose tissue, however collagen fibers localized around each individual adipocyte. The relative area occupied by collagen fibers (Figure 4) in the HCD group increased by 3.5 -fold compared to the control. Fibrosis level after application of PAS (group HCD+PAS) decreased by 2.4-fold compared to the HCD group, but still increased by 1.5 -fold in comparison to the control. 

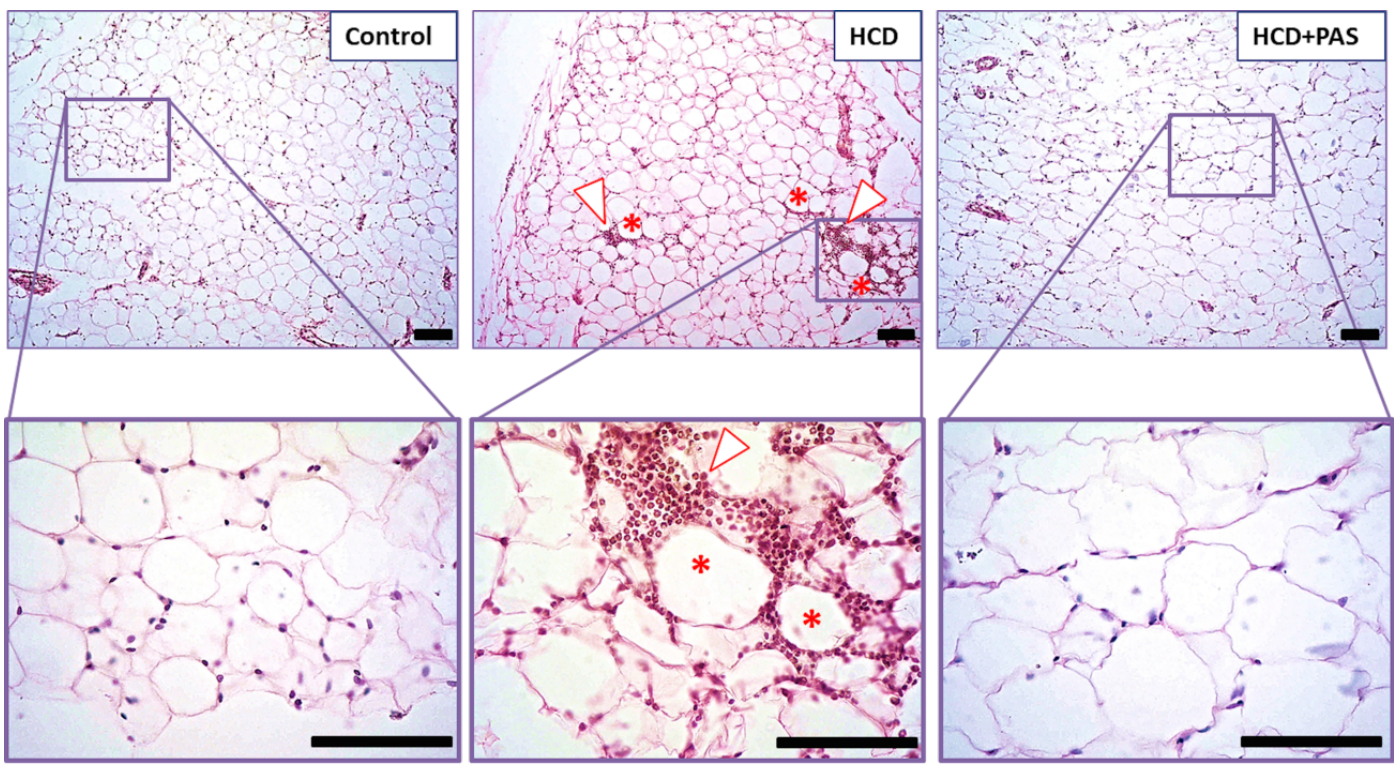

Figure 3. Microscopic appearance of the trichrome histochemical staining for fibrosis level detection in WAT sections of Control, HCD, HCD+PAS group: Van Gieson staining; scale bar $100 \mu \mathrm{m}$. Note, asterisk - crown-like structure, arrow head - leukocytes infiltration.

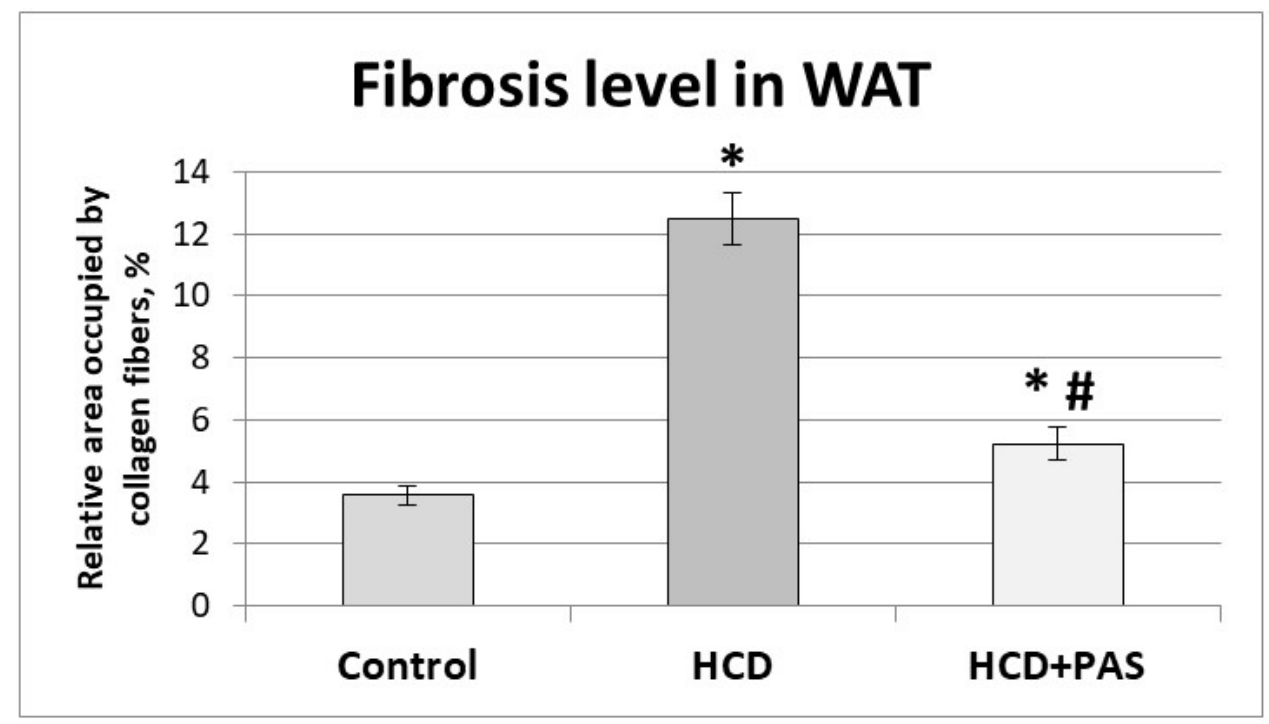

Figure 4. Fibrosis level in WAT. Data are presented as the $\mathrm{M} \pm \mathrm{SEM}$; * $-\mathrm{p}<0.05$ compared with control value, \# - $\mathrm{p}<0.05$ compared with HCD.

\subsection{Mast cells analysis in WAT.}

On WAT histophysiology also influences the mast cells presence. In control group mast cells localized near capillary and along connective tissue septa (Figure 5). In HCD group mast cells recruiting in adipose tissue lobules between septa, moreover they mainly were in degranulated state. In some cases, mast cells take part in the formation of CLS together with leukocytes. After oral administration of PAS (HCD+PAS group) the presence of mast cells in adipose tissue lobules fell, and they did not make CLS. The number of mast cells in WAT (Figure 6) in the HCD group increased by $55 \%$ in comparison to the control. In $\mathrm{HCD}+\mathrm{PAS}$ group the value of this parameter takes 
intermediate meaning - it’s not significantly differ from control and HCD group both.
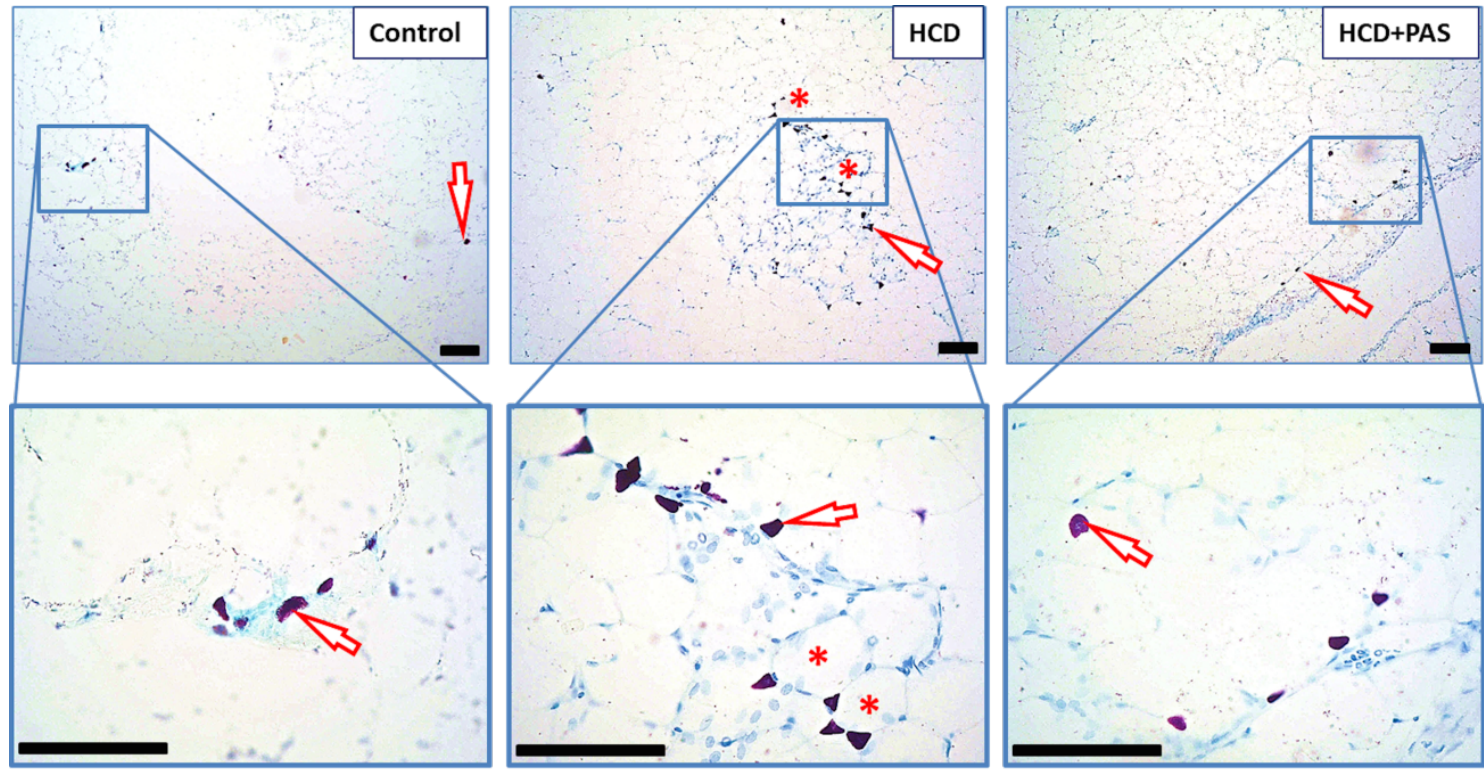

Figure 5. Microscopic appearance of the histochemical staining for mast cells detection in WAT sections of Control, HCD, HCD+PAS group: toluidine blue staining; scale bar $100 \mu \mathrm{m}$. Note, asterisk - crown-like structure, arrow - mast cells.

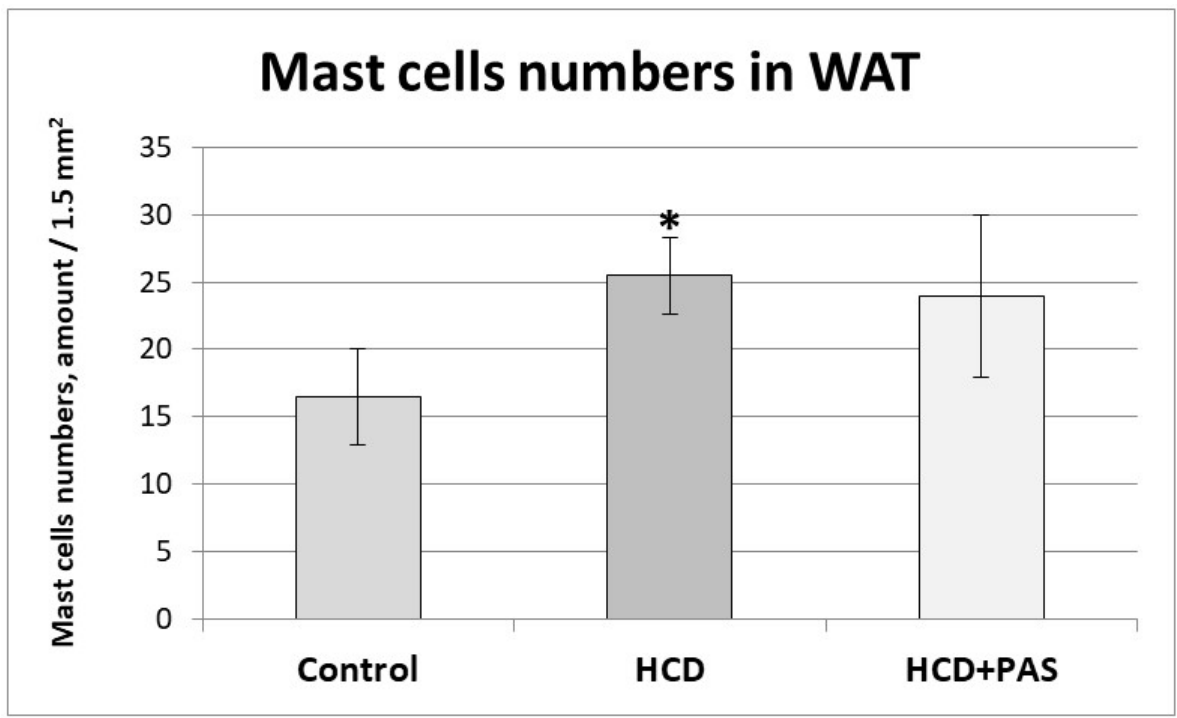

Figure 6. Mast cells detection in WAT. Data are presented as the $\mathrm{M} \pm \mathrm{SEM}$; * $-\mathrm{p}<0.05$ compared with control value, \# - $p<0.05$ compared with the HCD group.

\subsection{Discussions}

The results of this study clearly show that oral administration of functionally active peptides derived from the tissues of Adamussium colbecki significantly reduced the relative weight of visceral fat, the size of white adipocytes, the appearance of CLS, and the level of fibrosis in WAT of obese animals.

Given our previous data (Raksha et al., 2018; Raksha et al., 2019), we suggest that the beneficial effect of PAS may be partly realized through the influence on oxidative status, 
namely, the activity of key antioxidant enzymes and the level of lipid peroxidation products.

One of the explanations of the obtained data may be the anti-inflammatory and immunomodulatory properties of extracts derived from marine mollusks (Anmad et al., 2018). This coincides with our previous results - we observed the decrease in the concentration of the proinflammatory cytokine in obese animals, which received the peptide fraction. In a mouse model of lipopolysaccharide-induced acute lung inflammation, an application of hypobranchial gland extract from the Muricidae mollusk Dicathais orbita (the active compound is probably 6-bromoisatin) decreased the level of tumor necrosis factor $\alpha$ and interleukin-1 $\beta$ in bronchoalveolar lavage fluid (Ahmad et al., 2017). In addition, some mollusk peptides possess strong/moderate antitumor cytotoxicity and immune modulatory properties, which is provided by various terminal alkynylcontaining cyclic peptides - Dolastatin 17, Onchidin, Coololid-1, Kulokinalid-1 (explored mainly from marine mollusk Dolebella auricularia, marine pulmonate mollusk Onchidium sp., marine mollusk Philinopsis speciosa Pease, Marine cephalaspidean mollusk Philinopsis speciosa, respectively) (Chai et al., 2016). Some members of Bivalvia (Perna canaliculus and Anadara kagoshimensis) shown similar in vivo and in vitro anti-inflammatory effects, that manifested in inhibition of leukotriene production; inhibition of lipoxygenase products in arachidonic acid pathway; inhibition of cholesterol, TNF- $\alpha$, IL-1, IL-2, IL-6 biosynthesis; antioxidant potency; antiplatelet aggregation potency; fibrinolytic potency; reduction in neutrophil superoxide burst activity (Khan, et al., 2019). In all, marine natural product pharmacology for finding molecules with immune-modulatory properties is steadily developing and in the period of 2016-2017, it counted 313 marine compounds with novel pharmacological characteristics (Mayer et al., 2021).
Another explanation for the anti-obesity effect of PAS may be related to the gut microbiota (Ballini et al., 2020). PAS can be a probiotic substrate and influence the production of secondary metabolites by gut microorganisms. Mollusks have been shown to be an essential ingredient in the Mediterranean diet, which, if consumed for 12 months, stimulates the changes in microbiota - an increase in Roseburia and Oscillospira, a decrease in Prevotella, which result in an increase in insulin sensitivity in obese people (Haro et al., 2016). Many cohort studies between Mediterranean and non-Mediterranean diets demonstrated influence on the risk of development metabolic syndrome, obesity, type 2 diabetes mellitus, cancer, and neurodegenerative diseases (Lăcătuşu et al., 2019).

Only a few studies have demonstrated the influence of bioactive peptides derived from marine hydrobionts on obesity development (Jin et al., 2018). The investigation of di- and tripeptides from marine hydrobionts on human white pre-adipocytes showed a final (after differentiation) decrease in lipid content, downregulation of both PPAR $\gamma$ and $\mathrm{C} / \mathrm{EBP} \alpha$ expression (key regulators of adipogenesis) (Henda et al., 2015). Other studies showed effect of bioactive peptides derived from marine organisms on management of type 2 diabetes mellitus through a few mechanisms: protecting pancreatic $\beta$-cells, enhancement of glucose-stimulated insulin secretion, regulation of glucose uptake and lipid accumulation, regulation of the insulin-signaling pathways (for example, natural peptides display upregulation insulin receptors, phosphoinositide-3-kinase, translocation of glucose transporter protein GLUT4 and downregulation phosphatase and tensin homologue (PTEN)) (Xia et al., 2016). Also, the mechanisms of action on decrease hyperglycemia in case of type 2 diabetes mellitus proposed that natural peptides with $\alpha$ amylase and $\alpha$-glucosidase inhibitory activity (Siow et al., 2017; Mojica et al., 2017). 
However, further detailed studies are needed to integrate the applied methodology, dose, routes of administration, and mechanisms of action of mollusk-derived active peptides to the therapeutic treatment of obesity ( $\mathrm{Hu}$ et al., 2016) and metabolic syndrome.

\section{Conclusions}

The extract of functionally active peptides from the tissues of Antarctic scallop (PAS) Adamussium colbecki administrated to the obese rats have potential to stimulate partial recovery of white adipose tissue histophysiology and thereby promote therapeutic activity in obesity treatment.

\section{References}

Ahmad, T.B., Rudd, D., Benkendorff, K., Mahdi, L.K., Pratt, K-A., Dooley, L. et al. (2017). Brominated indoles from a marine mollusc inhibit inflammation in a murine model of acute lung injury. PLoS ONE, 12(10), e0186904.

Ahmad, T.B., Liu, L., Kotiw, M., Benkendorff, K. (2018). Review of anti-inflammatory, immune-modulatory and wound healing properties of molluscs. Journal of ethnopharmacology, 210: 156-178.

Altintas, M., Azad, A., Nayer, B., Contreras, G., Zaias, J. et al. (2011). Mast cells, macrophages, and crown-like structures distinguish subcutaneous from visceral fat in mice. Journal of Lipid Research, 52(3), 480-488.

Ballini, A., Scacco, S., Boccellino, M., Santacroce, L., Arrigoni, R. et al. (2020). Microbiota and Obesity: Where Are We Now? Biology, 9(12), 415.

Baty, J.J., Hwang, H., Ding, Z. (2007). The effect of a carbohydrate and protein supplement on resistance exercise performance, hormonal response, and muscle damage. The Research Journal of the NSCA, 21(2), 321-9.

Benedetti, M., Giuliani, M. E., Regoli, F. (2017). Pro-oxidant challenges and antioxidant adaptation of Pleuragramma antarctica in platelet ice. In The Antarctic Silverfish: a Keystone Species in a Changing Ecosystem (pp. 67-89). Springer, Cham.

Bhatia, R., Ullah, S., Hoque, M., Ahmad, I., Yang, Y. et al. (2021). Psychrophiles: A source of cold-adapted enzymes for energy efficient biotechnological industrial processes. Journal of Environmental Chemical Engineering, 9(1), 104607.

Cerrano, C., Calcinai, B., Bertolino, M., Valisano, L., Bavestrello, G. (2006). Epibionts of the scallop Adamussium colbecki (Smith, 1902) in the Ross Sea, Antarctica. Chemistry and Ecology, 22, 235-244.

Chai, Q.Y., Yang, Z., Lin, H.W., Han, B.N. (2016). Alkynyl-containing peptides of marine origin: A review. Marine drugs, 14(11), 216.

Cronin, K., Walker, S., Mann, R., Chute, A., Long, M. et al. (2020). Growth and longevity of the Antarctic scallop Adamussium colbecki under annual and multiannual sea ice. Antarctic Science, 32(6), 466-475.

Halenova, T., Raksha, N., Vovk, T., Savchuk, O., Ostapchenko, L. et al. (2018). Effect of C 60 fullerene nanoparticles on the dietinduced obesity in rats. International journal of obesity, 42(12), 1987-1998.

Haro, C., Montes-Borrego, M., Rangel-Zúñiga, O.A., Alcalá-Díaz, J.F., Gómez-Delgado, F. et al. (2016). Two healthy diets modulate gut microbial community improving insulin sensitivity in a human obese population. The Journal of Clinical Endocrinology, 101(1), 233-242.

Henda, Y.B., Laamari, M., Lanneluc, I., Travers, M.A., Agogué, H. et al. (2015). Di and tripeptides from marine sources can target adipogenic process and contribute to decrease adipocyte number and functions. Journal of Functional Foods, 17, 1-10.

Hu, X., Tao, N., Wang, X., Xiao, J., Wang, M. (2016). Marine-derived bioactive compounds with anti-obesity effect: A 
review. Journal of Functional Foods, 21, 372-387.

Jin, Q., Yu, H., Li, P. (2018). The evaluation and utilization of marine-derived bioactive compounds with anti-obesity effect. Current medicinal chemistry, 25(7), 861878.

Khan, B.M., Liu, Y. (2019). Marine mollusks: Food with benefits. Comprehensive reviews in food science and food safety, 18(2), 548564.

Lăcătușu, C.M., Grigorescu, E.D., Floria, M., Onofriescu, A., Mihai, B.M. (2019). The Mediterranean Diet: from an environmentdriven food culture to an emerging medical prescription. International journal of environmental research and public health, 16(6), 942.

Mayer, A., Guerrero, A.J., Rodríguez, A.D., Taglialatela-Scafati, O., Nakamura, F. et al. (2021). Marine Pharmacology in 20162017: Marine Compounds with Antibacterial, Antidiabetic, Antifungal, Anti-Inflammatory, Antiprotozoal, Antituberculosis and Antiviral Activities; Affecting the Immune and Nervous Systems, and Other Miscellaneous Mechanisms of Action. Marine Drugs, 19(2), 49.

Mishra, N., Wanjari, S., Parwani, R., Wanjari, P., Kaothalker, S. (2015). Assessment of collagen and elastic fibres in various stages of oral submucous fibrosis using Masson's trichrome, Verhoeff vangieson and picrosirius staining under light and polarizing microscopy. Journal of Dental Specialities, 3(2), 170-175.

Mojica, L., Luna-Vital, D.A., González de Mejía, E. (2017). Characterization of peptides from common bean protein isolates and their potential to inhibit markers of type- 2 diabetes, hypertension and oxidative stress. Journal of the Science of Food and Agriculture, 97(8), 2401-2410.

Raksha, N., Gladun, D., Savchuk, O., Ostapchenko, L. (2016). New fibrinogenases isolated from marine hydrobiont Adamussium colbecki. Journal of Biochemistry International, 3(1), 21-30.

Raksha, N., Potalitsyn, P., Yurchenko, A., Halenova, T., Savchuk, O. et al. (2018). Prevention of diet-induced obesity in rats by oral application of collagen fragments. Archives of Biological Sciences, 70(1), 7786.

Raksha, N., Halenova, T., Vovk, T., Yurchenko, A., Nikoliaeva, I. et al. (2019). Prevention of diet-induced obesity in rats by administration of peptides derived from marine hydrobiont. In Advances in Health and Disease, vol.11, (pp. 165-199). New York: Nova Science Publishers, Inc.

Raksha, N., Halenova, T., Kravchenko, O., Vovk, T., Savchuk, O. et al. (2020a). Purification and biochemical characterization of Trypsin-like enzyme from Antarctic Hydrobiont Adamussium Colbecki. Research Journal of Biotechnology, 15(1), 1-7.

Raksha, N., Udovychenko, I., Halenova, T., Vovk, T., Savchuk, O. et al. (2020b). Purification and biochemical characterization of fibrino(geno)lytic enzymes from tissues of Antarctic hydrobionts. Ukrainian Antarctic journal, 1, 69-81.

Salas-Salvadó, J., Díaz-López, A., RuizCanela, M., Basora, J., Fitó, M. et al. (2019). Effect of a lifestyle intervention program with energy-restricted Mediterranean diet and exercise on weight loss and cardiovascular risk factors: oneyear results of the PREDIMED-Plus trial. Diabetes Care, 42(5), 777-788.

Siow, H.L., Lim, T.S., Gan, C.Y. (2017). Development of a workflow for screening and identification of $\alpha$-amylase inhibitory peptides from food source using an integrated Bioinformatics-phage display approach: Case study-Cumin seed. Food chemistry, 214, 67-76.

Tuttolomondo, A., Simonetta, I., Daidone, M., Mogavero, A., Ortello, A. et al. (2019). Metabolic and vascular effect of the 
Mediterranean diet. International journal of molecular sciences, 20(19), 4716.

Xia, E.Q., Zhu, S.S., He, M.J., Luo, F., Fu, C.Z. et al. (2017). Marine peptides as potential agents for the management of type 2 diabetes mellitus - a prospect. Marine drugs, 15(4), 88.

\section{Acknowledgment}

This study was conducted as part of the theme «Implementation mechanisms of adaptive-compensatory reactions under the development of various pathologies» (№ 0111U004648) of Educational and Scientific Centre "Institute of Biology and Medicine," Taras Shevchenko National University of Kyiv.

\section{Conflicts of interest}

The authors have no conflicts of interest to declare. 